\title{
Pipeline cherrypicking deal yields lucrative return
}

Exelixis just presented phase 1 clinical trial data for three new kinase inhibitors at the 2006 American Society of Clinical Oncology annual meeting held in Atlanta, Georgia June 2-3. The compounds are included in a licensing and development deal with GlaxoSmithKline (GSK) that gives the pharma partner an option on 3 of 12 specified products in development. In structuring a deal to include options on multiple compounds, both GSK and Exelixis have lowered their risk while meeting the volume needs of a big pharma pipeline. This business model has yet to be proven successful before others will emulate it.

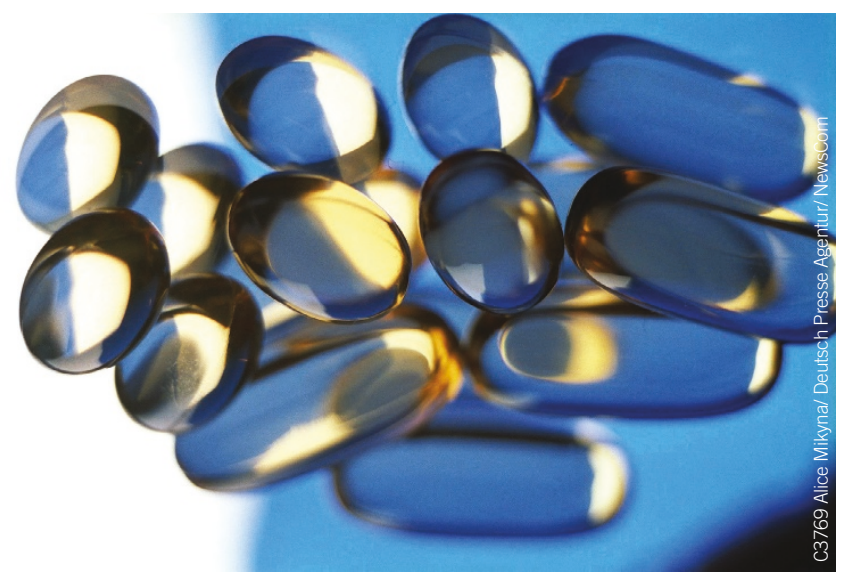

Take your pick: The new Exelixis-GSK deal allows the pharma company to cherrypick the biotech company's best kinase inhibitors.
Cowen's Schmidt, and it becomes even more impressive when one realizes that it competes directly with GSK's own internal drug discovery efforts.

But analysts caution that the deal has not produced a commercial drug yet, and they point to the VertexNovartis agreement signed in 2000. That deal is another multicompound agreement in protein kinase research and development that is similar in scope to the Exelixis-GSK deal. So far the agreement has failed to produce any significant commercial compounds for Vertex, of Cambridge, Massachusetts, or Novartis, of Basel, Switzerland. To some extent their work in the area So why would GSK give a company whose drug development efforts compete with their own a leg up? According to Exelixis CEO George Scangos, it goes to the overarching question for both big pharma and small drug developers as the industry moves into its fourth decade: "Can biotech produce compounds in a more cost-effective way?"

Scangos believes that the answer to that question is yes, and that Exelixis could prove it. With eight compounds in clinical development, the company has been successful in getting small molecules into clinical trials. Whether those compounds will develop into commercial products is another question.

Nevertheless, taking the company's licensing and partnering success as a whole, Exelixis could stand as a model for the potential of the drug development process in the mature biotech industry. Besides the GSK deal, the San Francisco-based Biotech company has other deals in place with partners including New York-based Bristol-Myers Squibb Company, South San Francisco's Genentech and Wyeth of Madison, New Jersey, and those deals guarantee the company at least $\$ 350$ million in funding, according to Eric Schmidt, biotech analyst at the investment bank SG Cowen in Boston. That cash could cover the company's expenses until 2008.

Take Exelixis's deal with GSK, for example. First inked in 2002, the deal, according to the company's US Securities and Exchange Commission $8 \mathrm{~K}$ filing, gives GSK an option on any 3 of 12 specified compounds under development by Exelixis (XL784, XL647, XL999, XL880, XL184, XL820, XL844 and five earlier-stage programs) and allows GSK to retain the rights to 32 specified targets. GSK can pick from among the selected compounds at the proof-of-concept stage, defined as phase 2 a clinical development. If they choose three compounds at this stage, they could pay Exelixis up to $\$ 275$ million in milestone payments, plus associated development milestones and sales royalties, provided the compounds make it into commercial development.

That cash is important: for biotech companies to produce drugs in a more cost-effective way, they must be able to spend more money, according to Scangos. He also says that the company with one or two compounds in development does not have the critical mass to compete. Even if they are twice as smart, they are still going to have a lot of failures. He stresses that whereas reaching goals is dependent on execution (that is, having output that is productive), there are some things companies can do to improve their odds.

And the deal with GSK helps Exelixis do just that. As a gesture of faith in the deal, GSK agreed to a modification to the agreement in January 2005 that provides for accelerated milestone payments for filing investigational new drug applications based on the compounds or for successful phase 1 trials on any one of the compounds completed in 2005. Under this new agreement, Exelixis has already received payment for one compound. In addition, the modification called for research funding of $\$ 47.5$ million over the life of the agreement and another $\$ 5$ million payment on unspecified milestones. This is on top of the fully drawn $\$ 85$ million line of credit GSK gave in the original deal. And, for good measure, GSK bought a million shares of newly issued Exelixis stock at a $25 \%$ premium to the 2004 share price.

The deal is an impressive licensing agreement worth close to $\$ 500$ million before the commercialization of any compound, according to SG looks largely theoretical, whether intended that way or not. Novartis has selected one compound, VX-322 (a new dual Flt3/c-Kit kinase inhibitor), from among the covered compounds for preclinical in 2004, but so far the compound has not made enough progress to be included in the official Novartis pipeline table.

However, according to Michael Partridge, director of corporate communications for Vertex, it is the ability to retain the rights to compounds their partner does not pick up that provides good value. In 2004, for example, Merck of Whitehouse Station, New Jersey entered into collaboration with Vertex to develop and commercialize VX-680, a kinase inhibitor used for cancer treatment that was included in the original development agreement with Novartis but that Novartis failed to pick up. The Merck deal includes \$34 million in up front and research payments, plus up to $\$ 350$ million in milestone payments. VX-680 just entered phase 2 trials in April 2006.

Scangos, then, has the confidence of a person who knows where he's going, because the road he's traveled so far has been the correct one, if measured by getting compounds into the clinic. After all, Exelixis already has phase 1 data for three compounds covered under the agreement and a big pipeline that made the deal practical for both sides.

And that does not take into account the successes that Exelixis has had with other compounds and other collaborations, which include five other compounds in the clinic and which Scangos believes have so far validated their approach. "When we set goals, we don't miss them. And we have the pipeline to back that up," he says.

John Ransom, Lone Tree, Colorado 